\title{
CUIDANDO DE UM FAMIIIAR COM CÂNCER
}

\section{Taking Care of a Family Member with Cancer}

\author{
Ana Claudia N. S. Wanderbroocke ${ }^{1}$
}

\section{Resumo}

Pesquisa qualitativa que visa a levantar os fatores que norteiam a dinâmica familiar no processo de organização dos cuidados oferecidos ao paciente com câncer. Observou-se que a família tanto reproduz padrões culturais como também usa estratégias particulares, de acordo com seu próprio funcionamento para dar conta desta tarefa. Os dados apontam para a qualidade do relacionamento familiar, o papel desempenhado pelo cuidador principal e pelo paciente e para a busca de sentido para a experiência vivenciada.

Palavras-chave: Cuidadores; Família; Câncer; Psico-oncologia.

\section{Abstract}

Qualitative survey that aims at appraising the factors that surround the familiar dynamics in the process of organizing the care offered to patients with cancer. It was observed that the family reproduces cultural patterns, as it uses private strategies, according to its own role, in order to handle this task. The data points out to the quality of the family's relationship, the role fulfilled by the main caregiver and the patient, and the search for a meaning for the lived experience.

Keywords: Caregivers; Family; Cancer; Psycho-oncology.

1 Psicóloga, Mestre em Psicologia Clínica pela PUCSP, Supervisora do Serviço de Psicologia Clínica do Hospital Erasto Gaertner. Endereço para contato: R. Dr. Ovande do Amaral, 201 CEP: 81.520-060, Curitiba-PR.

E-mail: awander@lpcc.org.br 
A atenção à família é parte fundamental do atendimento ao paciente com câncer, uma vez que ela representa a principal fonte de apoio durante todo o processo de tratamento.

Quando um dos membros da família adoece e necessita de cuidados especiais e/ou sistemáticos, entram em cena as dinâmicas de funcionamento do sistema familiar a fim de decidir como os cuidados serão prestados.

Uma vez que o cuidador envolve-se em toda uma problemática pessoal, familiar e social, é importante identificar os fatores que norteiam a dinâmica existente no processo de organização dos cuidados oferecidos ao paciente pela família a fim de podermos oferecer uma assistência mais efetiva a nossa clientela.

\section{Revisão de Literatura}

A família desempenha importante papel na transmissão de costumes e valores na nossa sociedade. Velho (1987) considera a família uma instituição fundamental no processo de socialização da subjetividade mesmo naquelas em que a ideologia individualista é altamente considerada, uma vez que a família nuclear não permanece isolada. Considera que a família tem um grau de estabilidade maior do que se costuma considerar e que é uma instituição que organiza a sociedade. DaMatta (1989), sobre a família brasileira, diz que há uma 'escolha' por parte da sociedade, que a valoriza e a institucionaliza como fundamental à própria vida social. Assim, a família é um grupo social, bem como uma rede de relações.

O homem, por sua vez, não pode ser pensado independentemente de seu contexto uma vez que tanto a constituição do sujeito como do meio se dá a partir das trocas recursivas entre os elementos de um e de outro. É neste movimento contínuo de trocas, de influenciar e ser influenciado que tanto a sociedade, as famílias, como os indivíduos vão se constituindo.

O conceito de família inscreve as normas e valores sociais, ou seja, o que é esperado socialmente das pessoas enquanto indivíduos e grupos familiares. Desta forma, o cuidar no âmbito doméstico fica obscurecido quando entendido como função natural e sem que se busque entender a dinâmica intrínseca a este processo, bem como as consequências do mesmo. (Wanderbroocacke, 2001)
Neste sentido é importante ressaltar as mudanças ocorridas na estrutura das famílias que podem refletir na sua capacidade de oferecer cuidados aos seus membros doentes. Berquó et al (1998), analisando dados obtidos de recenseamentos realizados nas últimas décadas no Brasil, observa que desde 1950 transformações nos arranjos familiares vêm se tornando mais evidentes. As maiores transformações vêm ocorrendo no núcleo familiar e dizem respeito à diminuição do número de integrantes, ao aumento do número de uniões conjugais sem vínculos legais, aos arranjos monoparentais e, principalmente, à posição relativa da mulher e aos novos padrões de relacionamento entre os membros, tendendo da passagem de relações hierárquicas para relações igualitárias, o que é mais visível nas camadas médias urbanas, passando com o tempo a permear as camadas mais populares.

Estas mudanças nas famílias são consequências das transformações sociais que tiveram início com a Revolução Industrial, exigindo um número maior de mão-de-obra nas indústrias, incentivando os movimentos urbanos do campo para as cidades e fazendo com que as mulheres ingressassem no espaço público, antes domínio masculino, alterando conseqüentemente a vida doméstica.

Walsh (1995) destaca como a tensão gerada na família pelos cuidados prolongados de um membro dependente só recentemente tem merecido atenção e que as mulheres são cada vez mais sobrecarregadas pelas exigências físicas e emocionais conflitantes, na medida em que as responsabilidades profissionais se justapõem às expectativas de seu papel tradicional de cuidadoras.

Cantor (1983) afirma que existe uma tendência a se denominar todos os que prestam cuidados ao paciente numa categoria única, a de cuidadores ou de assumir que todo cuidador informal (que não faz parte da equipe de saúde) é um familiar e principalmente uma mulher. Esta homogenização das variáveis, segundo o autor, tende a obscurecer as diferenças entre os vários grupos de cuidadores e os tipos de estresses que cada grupo pode estar sofrendo no processo de prestar assistência.

Mendes (1995) revisou alguns estudos que buscam entender como as pessoas se comprometem com a atividade de cuidar. Para muitos cuidadores trata-se de um "impulso", ou de um proces- 
so de "escorregar para dentro" (slipping into it). A maioria dos cuidadores vê o processo como natural, atribuindo-o a graus diferentes de ligação afetiva, dever e obrigação como o compromisso ao juramento feito ao casar, ao desejo de retribuir os cuidados na infância, ao horror à idéia de asilamento, troca de favores e a ausência de outras alternativas. Embora a designação do cuidador seja informal e decorrente de uma dinâmica, o processo parece obedecer certas regras relativas a quatro fatores:

a) parentesco: com freqüência maior para os cônjuges, antecedendo sempre a presença de algum filho; mulher;

b) gênero: com predominância para a

c) proximidade física: considerando quem vive com a pessoa que requer cuidados;

d) proximidade afetiva: destacando a relação conjugal e a relação entre pais e filhos.

Sendo assim, 0 ato de cuidar de um familiar doente assume um perfil feminino, é geralmente restrito à família nuclear e também é exercido, em grande parte, por uma única pessoa.

Horowitz (1985) pesquisou as diferenças entre homens e mulheres ao prestarem cuidados aos familiares. Encontrou dados de que o padrão é que os homens assumam o papel de cuidadores somente na ausência de uma mulher disponível. Isto não significa falta de sentimentos familiares ou negligência masculina, mas uma definição cultural de comportamento apropriado por gênero. Da mesma forma, quando os homens assumem os cuidados, tendem a dar menor suporte extensivo e a ter menos experiências estressantes do que as mulheres porque, apesar de assumirem os cuidados, ajudam menos freqüentemente em tarefas instrumentais (higiene, por exemplo).

Nolan et al. (1996) apontam para o fato de que a literatura sobre cuidadores tem explorado pouco os aspectos longitudinais e que é de grande importância entender como os cuidados se dão ao longo do tempo. Consideram que, apesar de cada situação ser única, delimitar estágios ajudaria a predizer certos tipos de necessidades. A respeito de como os cuidados são oferecidos pela família, acreditam que o relacionamento prévio entre cuidador e pessoa cuidada exerce influência significativa para o início, para como este processo se dá e para o seu desfecho. Entender o cuidar, para os autores, requer considerar a natureza e a qualidade das interações passadas.

\section{Método}

Trata-se de uma pesquisa qualitativa uma vez que esta abordagem, segundo Triviños (1987), tem 0 ambiente natural como fonte direta dos dados e o pesquisador como instrumento-chave, é descritiva, preocupa-se com o processo e não simplesmente com os resultados e o produto, os pesquisadores tendem a analisar seus dados indutivamente e o significado é a preocupação essencial.

Dentro da abordagem qualitativa alia-se e destaca-se o método clínico, que pode ser entendido como a descrição do homem num determinado momento e numa determinada cultura. Desta forma, busca-se compreender um determinado fenômeno social, interagindo diretamente com os sujeitos, coletando os dados relativos à sua vivência subjetiva e aos seus significados, ao mesmo tempo, percebendo a importância da análise da subjetividade do pesquisador, na medida que são as relações estabelecidas entre ele e os sujeitos que garantem a qualidade dos dados e a validade da pesquisa.

Os sujeitos foram 10 familiares responsáveis pelos cuidados (cuidadores principais), há no mínimo 90 dias, de um paciente adulto (25 anos ou mais) com câncer, dependente e acamado a maior parte do dia. Optou-se por este recorte cuidados dispensados aos adultos doentes - uma vez que cuidar de crianças e adolescentes traz especificidades que merecem ser consideradas à parte, em outro estudo. O tratamento para o câncer estava em andamento em um hospital especializado em Curitiba-PR. Esta instituição caracteriza-se por atender pessoas de médio e baixo nível socioeconômico, sendo a ampla maioria de sua clientela vinculada ao S.U.S. Os sujeitos consentiram em participar da pesquisa atendendo as Diretrizes e Normas Regulamentadoras de Pesquisa Envolvendo Seres Humanos (Resolução CNS 196/ 96) que garante, entre outros aspectos, o sigilo em torno de suas identidades, por isso nomes fictícios foram utilizados.

Como instrumentos foram utilizados genogramas familiares e entrevistas semi-estruturadas, constando de um roteiro básico, mas com possibilidade de abertura para questões conside- 
radas significativas para cada caso. Os genogramas serviram de base para a análise da estrutura e do funcionamento das famílias e como apoio para a realização das entrevistas. Estas foram analisadas estabelecendo-se categorias, visando ao levantamento dos principais temas emergentes. Os resultados foram obtidos a partir da análise descritiva realizada com cada uma das entrevistas uma vez gravadas e transcritas na íntegra.

\section{Discussão}

O primeiro fator identificado nas famílias que norteia a organização dos cuidados oferecidos ao paciente, como exposto na literatura, é a presença das mulheres como cuidadoras principais. Elas costumam ser as pessoas que dedicam mais tempo aos cuidados da pessoa doente e exercem mais os cuidados com o corpo (higiene pessoal, curativos, alimentação, administração de medicamentos). Assumem papel central nos cuidados oferecidos pela família ao doente. Os homens costumam estar mais presentes em tarefas indiretas como visitas, apoio, necessidades externas ao lar (compras, deslocamentos ao hospital, marcação de consultas) de apoio aos cuidadores principais.

De acordo com Mendes (1995), é comum que a pessoa que se torna a principal cuidadora diga ter assumido esta função espontaneamente, sem um questionamento prévio ou discussão com o restante do grupo familiar sobre quem desempenharia os cuidados. Nesta decisão costumam ser explicitados fatores como relacionamento afetivo, como no caso da esposa de Célio: É por causa do amor. Sem o amor a gente não ia conseguir; grau de parentesco, morarjunto ou próximo, maior disponibilidade de tempo ou indisponibilidade dos demais, exemplificados pela esposa de João: A família dele sou eu, eu sou a esposa, a gente mora junto, eu é que tenho que cuidar, não tem outros. Os irmãos trabalham ... Os filhos todos trabalham, eu fico em casa; gênero, a filha de Ema diz: Eu falei vou cuidar da mãe ... Tem os meus irmãos mas eles são todos homens e trabalham. Eu não trabalho, então eu não vou abandonar a mãe; maior liderança nas questões domésticas, estrutura emocional, relatados pela esposa de Ari: A vida fez assim. Estou em casa com meu marido e eu que estou mais cônscia, sempre cuidei de tudo em casa. Ele está em cadeira de roda e tudo ... en tão é lógico que eu vou cuidar; e maior familiaridade com doenças e cuidados de doentes, caso trazido pela filha de Mário que fala de sua cunhada, a cuidadora dele: Ela é uma pessoa muito dócil, cuidou da mãe dela que morreu anos atrás, no entanto cuida da minha mãe como se fosse a mãe dela. Até no trato com meu pai (que é o paciente oncológico) é ela que faz a higiene dele. Eu disse para meusirmãos que ela não era obriga da a cuidar, mas ela tem muita paciência e está pegando a maior parte pesada.

Porém, estes fatores demonstram seguir a dinâmica familiar existente a partir das relações estabelecidas entre as pessoas, que por sua vez lhes atribuem significados e dão sentido para as experiências vividas.

Nestas dinâmicas relacionais, um dos fatores importantes na organização dos cuidados oferecidos ao paciente adulto é o papel desempenhado pelo cuidador na família. A cuidadora principal de Esther relata que é a filha mais velha e que perderam o pai muito cedo. Assim ela aliouse à mãe para dar conta da criação dos irmãos menores e desta forma: Eu acho que com isto, sem querer eu passei a ser o braço direito da mãe e dos irmãos. Então hoje eles esperam que eu tome as decisões. O filho de Paulo conta que: Eu sempre fui assim, procurando incentivar a família. Eu sempre fui procurado para colocar ordem para cada um. Então eu assumi a administração da casa. Tanto que os outrosirmãos con cordaram e hoje eu estou com o pai e a mãe junto, estou cuidando deles. Os outros saíram, foram fazer para si. A sobrinha de Sônia relembra o relacionamento anterior em que: Sempre foi assim, eu sou desse tipo de pessoa que se não posso ajudar pelo menos eu conforto, escuto. Eu sempre procurei ajudar ela da melhor maneira possível e eu acho que ela trouxe isto para ela agora neste momento em que ninguém mais quer cuidar dela. Estas narrativas a respeito da história passada conferem uma peculiaridade à identidade destas pessoas, a de estarem voltadas e atentas ao bem-estar dos demais, mesmo em outros contextos e dando um sentido tanto para suas vidas como para a função assumida atualmente junto ao doente.

Em contrapartida, também temos o papel desempenhado pelo próprio paciente e a influência deste para a qualidade do relacionamento com a família e com o cuidador. Sobre Esther, que de- 
dicou a vida à família e que hoje tem todos os filhos e netos participando de seus cuidados, é dito: Nós usávamos muito ela. Nós sempre estávamos na casa dela. A mãe cuidava dos netos ... sempre foi assim. Ela foi nosso pai e nossa mãe junto, nosso a poio era ela, pelo coração bom que ela tem. Então, a hora que ela ficou doente, nós começamos a tirar a responsabilidade dela e assumir ela. Ela tem aten ção de todos. Os netos sempre que podem estão em volta da cama dela, é natural, não é imposto. Helena tem dois filhos adultos, quatro irmãs e os pais, apenas uma das irmãs se dispôs a assumi-la na doença: Ela mesma diz que foi a ovelha negra da família ... Antes da doença ela sempre foi uma pessoa muito rígida, então a gen te não era de se chegar muito com ela, a gente era mais distante. Ela falava umas coisas para a mãe que ofendia, ofendia a gente. A gente se retirava, não falava mais com ela ... Ema é cuidada pela filha, tem mais quatro filhos homens e o marido. A filha assumiu sozinha a tarefa de cuidar, mesmo casada e tendo sua própria casa e filhos. Manteve uma forte relação afetiva com a mãe, faz questão de estar com ela e sobre isso relata: Agora não tem mais graça porque ela era a estrutura da família, sabe? Porque a gente chegava e ela estava ali, alegre, sempre vin ha acolher os filhos, os netos e agora ela não está mais para acolher a gente. Quando ela se for vai se desestruturar a família toda. Os filhos se incomodam muito com o sofrimento dela. Nossa! Se eu ficar lá em casa eu morro se não cuidar dela! Porque ela é tudo para mim.

Nesses exemplos, temos narrados pelos atuais cuidadores como as pessoas por eles hoje cuidadas estabeleceram seus vínculos afetivos com os membros da família e como estes vínculos foram percebidos possibilitando sua manutenção. As percepções de cada um, traduzidas em suas histórias de vida, justificam o fato de terem assumido os cuidados e as condições atuais dos cuidados oferecidos.

Grandesso (2000) coloca que desde muito cedo as histórias fazem parte da vida das pessoas em diferentes culturas e diferentes tempos. Oferecem explicações organizadas da ação humana, sendo também uma maneira de nos fazermos inteligíveis em nosso mundo social. Construímos histórias que nos ajudam a organizar nossas conquistas e dissabores desde a infância e por toda a vida adulta. Ao construirmos nossas histórias, expressando a maneira como compreendemos nossa experiência, não só estamos nos apresentando aos outros, mas também a nós mesmos, além de estarmos ampliando ou restringindo nossas possibilidades existenciais. As histórias representam, assim, o resultado de empenhos para dar um sentido à vida, organizando a experiência em seqüências temporais, configurada em relatos coerentes sobre nós mesmos e nosso mundo. Uma narrativa só pode constituir-se à medida que acontecimentos passados são conectados a acontecimentos presentes e a desdobramentos futuros possíveis, em uma seqüência linear que, brindando a pessoa com um sentido de continuidade da existência, oferece-lhe um marco referencial para interpretar sua cotidianidade e construir seus futuros possíveis. Assim: "...vivemos nossas narrativas e nossas narrativas tornam-se nossas vidas; nossas realidades tornam-se nossas histórias e nossas histórias tornam-se nossas realidades." (Anderson, 1997, p. 216).

A história familiar vai sendo construída com base nos relacionamentos interpessoais que estabelecem a identidade de cada um dentro do sistema. O elemento essencial para os relacionamentos é o amor, base da vida afetiva que, ao longo do tempo, dependendo de como esta se dá, as relações vão se moldando e caracterizando. A partir dos exemplos acima citados, vemos que os colaboradores apontam fatos de suas histórias de vida, organizados em narrativas ao redor de características vistas em si próprios e nos outros, que explicam, dão um sentido racional para o fato de estarem cuidando no presente.

Maturana (2001) considera que o amor é o fundamento do fenômeno social e não uma conseqüência dele, e que os fenômenos sociais, em um domínio qualquer de interações, duram somente enquanto o amor persistir nesse domínio. Diz que somos acostumados a pensar em nós mesmos como animais racionais, mas que somos, na verdade, animais que utilizam a razão, a linguagem, para justificar nossas emoções e que "o que é especialmente humano no amor não é o amor, mas o que fazemos no amor enquanto humanos" (p.185).

Seguindo este ponto de vista, só há relacionamento humano enquanto houver amor, do contrário as pessoas não se relacionam. Então, só é possível cuidar enquanto o amor existe de alguma forma, pois ser cuidador é ser aquele que cuida da dor do outro e isto só pode existir na rela- 
ção. Se existe alguém cuidando é porque o amor está presente, mesmo sendo manifestado em diferentes sentimentos, que traduzem a forma como foi vivenciado na história de cada um. A história passada conecta-se à decisão do presente de estar cuidando, com vistas a um objetivo futuro, que pode ser identificado nas narrativas dos cuidadores.

Sobre esse aspecto, a cuidadora principal de Esther comenta: Eu estou pagando aquilo que ela fez por mim, aquela atenção, aquele cuidado que ela sempre me deu. É uma forma de retribuir. Ninguém vai sentir por não ter feito algo por ela, vamos fazer agora para não chorar depois ... tanto é que a gente tem em mente que o dia que ela sair dessa, então daí nós vamos ter paz e que ela vai ter paz, porque nós fizemos tudo na vida quanto era necessário. Da mesma forma o irmão de Luiz que o acompanha diariamente diz: Para mim é muito importante estar presente. Só lamento não poder ajudar mais, só posso ajudar com a minha presença aqui. Quando eu saio eu me sinto bem, quando eu sinto que ele está satisfeito com a conversa, eu vejo que ele gosta disso. Ele gosta de ter alguém dos parentes junto. Então eu também fico contente com isso. Já a filha de Dalva aponta para um contexto diferente entre cuidador e pessoa cuidada: Antes (de ela adoecer) era cada uma para um lado... A gente sempre brigou, eu ea mãe, mas eu sempre fui apegada a ela. Acho que isto está me fazendo sofrer demais. Eu ter brigado tanto com ela e agora saber que ela está nesta situação. Sei lá, me arrependo de tudo que eu fiz, das brigas, então eu acho que isto faz com que eu sofra demais. De uma maneira semelhante, a irmã de Helena explica como veio a ser sua principal cuidadora: Eu não me dava com ela ... desde que tivemos um atrito com ela e fiquei três anos sem conversar com ela, mas como aconteceu tudo isso aí (a doença) eu deixei tudo de lado evou tentar ajudar ela com amor e com carinho. Eu fiquei com peso na consciência ... não foi eu que procurei a confusão, mas me senti assim ... Célio é um paciente considerado terminal, sua esposa reflete sobre os cuidados e conclui: Ele tem muito, muito mais cabeça do que eu, apesar de todos os problemas dele. Ele é a pessoa mais madura, mais clara da minha vida. Não posso permitir que nada lhe aconteça (fazendo menção a sua morte). A filha de Ema, mesmo esgotada após meses seguidos de cuidados prestados dia e noite à mãe, afirma: Eu faço qualquer coisa, eu faço tudo, mas não vou deixar ela morrer, ela não pode me deixar!

Os cuidadores de Esther e Luiz manifestam a possibilidade de poder retribuir com a atenção dispensada ao familiar, hoje doente, aquela que receberam no passado. Já no caso das cuidadoras de Dalva e Helena a intenção presente é, pode-se dizer, a de reparar algo do passado, algo considerado errado pelas cuidadoras em suas próprias atitudes e que a situação de cuidado possibilita rever. As cuidadoras de Célio e Ema buscam por meio dos cuidados oferecidos impedir que a relação seja alterada, isto é, buscam a qualquer custo a recuperação da pessoa doente para que ela não deixe de assumir, ou para que possa voltar a assumir o seu lugar na relação já estabelecida. Ainda, é uma forma de fazer valer a própria identidade de cuidador que a situação de cuidar constrói e/ou reafirma e que o contexto social reconhece, dignificando e aprovando aquele que o faz.

\section{Considerações Finais}

Ao cuidar de uma pessoa que adoece, a família tanto estará criando sua própria forma de lidar com a situação como também estará reproduzindo padrões sociais, na medida que os valores atuais continuam respondendo à expectativa de que os cuidados ao doente sejam levados a cabo pela família respeitando as relações de parentesco (maior ou menor proximidade) e exercido preferencialmente por uma mulher.

Mas cada família também traz a sua particularidade ao organizar-se para cuidar e essas pertencem ao âmbito das relações, nas quais os papéis e funções são desempenhados moldando a identidade de cada integrante e construindo a história da família. Com base nisso, as narrativas dos sujeitos desta pesquisa apontaram para alguns dados:

- as famílias tendem a eleger um cuidador principal sem que este acordo seja explicitado entre os membros;

- o papel de cuidador principal costuma ser assumido por aquele membro que vinha desempenhando funções mais próximas da necessidade atual (a de cuidar), mantendo a coerência no funcionamento familiar;

- a qualidade do relacionamento prévio 
determina a permanência ou o rompimento dos vínculos afetivos e o cuidar só se dá na permanência destes. Do contrário, teríamos o abandono da pessoa doente;

- o cuidador principal assume este papel visando a atingir um propósito de acordo com a qualidade das relações estabelecidas no passado, construindo uma seqüência linear de coerência e dando um sentido à história de vida;

- algumas razões para assumir os cuidados são: retribuição, reparação, reconstituição da relação anterior, manutenção do papel.

Vale ressaltar que esta pesquisa foi realizada com cuidadores que fazem parte de uma família com estrutura suficiente para arcar com os cuidados da pessoa doente, o que algumas vezes não é encontrado, situação que merece atenção por parte dos pesquisadores. Como foi dito no início, a família é a principal fonte de apoio ao paciente oncológico e, portanto, cuidar de como ela vem cuidando é uma maneira de ampliar o foco de ação profissional para o contexto dos cuidados oferecidos.

\section{Referências}

Anderson, H. (1997). Conversation, language and possibilities: a postmodern approach to therapy. Nova Yorque: Basic, 1997.

Berquó et al. (1998). Arranjos familiares no Brasil: uma visão demográfica.. Em F. Novaes \& L.M. Schwarcz.(Orgs.), História da vida privada no Brasil: contrastes da intimidade contemporânea. São Paulo: Companhia das Letras.

Cantor, M.H. (1983). Strain among caregivers:a study of experience in the United States. Gerontologist, 23 (6):597-604.

Da Matta, R. (1989). A família como valor: considerações não-familiares sobre a família brasileira. Em A.M. Almeida (Org.), Pensando a família no Brasil: da colônia à modernidade. Rio de Janeiro: Espaço e Tempo.

Grandesso, M.(2000). A. Sobre a reconstrução do significado. Uma análise epistemológica e hermenêutica da prática clínica._São Paulo: Casa do Psicólogo.
Horowitz, A. (1985). Sons and daughters as caregivers to older parents: differences in role performance and consequences. Gerontologist, 25 (6): 612-17.

Maturana, H. R.(2001). Reflexões sobre o amor. Em H.R. Maturana, C. Magro, M. Graciano \& N. Vaz(Orgs.), A ontologia da realidade. Belo Horizonte: UFMG.

Mendes, P.B.M.T. (1995). Cuidadores: heróis anônimos do cotidiano. Dissertação de Mestrado Não-Publicada, Pontifícia Universidade Católica de São Paulo. São Paulo, SP.

Miermount, J. (1994) Dicionário de terapias familiares: teoria e prática. Porto Alegre: Artes Médicas.

Nolan, M., Grant,G., \& Keady. J. (1996). Understanding family care. A multidimensional model of caring and coping. Buckingham: Open University Press.

Triviños, A. N. S. (1987). Introdução à pesquisa em ciências sociais. A pesquisa qualitativa em educação. São Paulo: Atlas.

Velho, G. (1987). Família e subjetividade. Em A.M. Almeida. Pensando a família no Brasil: da colônia à modernidade. Rio de Janeiro: Espaço e Tempo.

Walsh, F. (1995) A família no estágio tardio da vida. Em B. Carter \& M. McGoldrick. As mudanças no ciclo de vida familiar. Uma estrutura para a terapia familiar. Porto Alegre: Artes Médicas.

Wanderbroocke, A. C. N. S. (2001). O funcionamento da família do idoso com câncer: Tornando-se cuidadores. Dissertação de Mestrado Não-Publicada, Pontifícia Universidade Católica de São Paulo. São Paulo,SP.

Recebido em/ received in: 10/02/2004 Aprovado em/ approved in: 01/03/2005 